\title{
C3d regulates immune checkpoint blockade and enhances antitumor immunity
}

\author{
Jeffrey L. Platt, ${ }^{1}$ Inês Silva, ${ }^{2}$ Samuel J. Balin, ${ }^{3}$ Adam R. Lefferts, ${ }^{2}$ Evan Farkash, ${ }^{4}$ Ted M. Ross,,${ }^{5}$ \\ Michael C. Carroll, ${ }^{6}$ and Marilia Cascalho ${ }^{1}$ \\ 'Department of Microbiology and Immunology, ${ }^{2}$ Department of Surgery, University of Michigan, Ann Arbor, Michigan, USA. \\ ${ }^{3}$ Department of Dermatology, UCLA, Los Angeles, California, USA. ${ }^{4}$ Department of Pathology, University of Michigan, \\ Ann Arbor, Michigan, USA. ${ }^{5}$ Center for Vaccines and Immunology, Department of Infectious Diseases, The University of \\ Georgia, Athens, Georgia, USA. 'Department of Pediatrics, Graduate Program in Immunology, Harvard Medical School, \\ Boston, Massachusetts, USA.
}

Despite expression of immunogenic polypeptides, tumors escape immune surveillance by engaging T cell checkpoint regulators and expanding Tregs, among other mechanisms. What orchestrates these controls is unknown. We report that free C3d, a fragment of the third component of complement, inside tumor cells - or associated with irradiated tumor cells and unattached to antigen - recruits, accelerates, and amplifies antitumor T cell responses, allowing immunity to reverse or even to prevent tumor growth. C3d enhances antitumor immunity independently of B cells, NK cells, or antibodies, but it does so by increasing tumor infiltrating CD8+ lymphocytes, by depleting Tregs, and by suppressing expression of programmed cell death protein 1 (PD-1) by T cells. These properties of $\mathrm{C} 3 \mathrm{~d}$ appear specific for the tumor and dependent on complement receptor 2 , and they incur no obvious systemic toxicity. The heretofore unrecognized properties of free C3d suggest that protein might determine the effectiveness of immune surveillance and that increasing availability of the protein might prove advantageous in the treatment or prevention of cancer and premalignant conditions.

Conflict of interest: $M C$ and $J \mathrm{LP}$ are inventors on a pending patent for use of C3d as a cancer therapeutic.

Submitted: August 17, 2016

Accepted: April 4, 2017

Published: May 4, 2017

Reference information: JCI Insight. 2017;2(9):e90201. https:// doi.org/10.1172/jci.insight.90201.

\section{Introduction}

Recent reports showing that immune checkpoint inhibitors can facilitate the emergence of protective immunity and control of malignancies $(1,2)$ confirm the idea that immune surveillance can provide a primary defense against malignant transformation and that abrogation of immune surveillance might be a key step in the development of cancer. Immune surveillance of cancer (and normal) cells is abrogated at certain checkpoints by activation of the PD-1/PD-L1 pathway and by the actions of Tregs and regulatory B cells, among other mechanisms (3). Still unclear, however, is how tumor cells and normal cells determine whether to engage these regulatory mechanisms. Here, we report observations suggesting that complement proteins could have a pivotal role in favoring immune surveillance over immune regulation.

The complement system consists of more than 50 proteins - some circulating in the blood, others bound to cell membranes. The complement system is activated by antibodies, lectins, and the surface of damaged or foreign cells, but also spontaneously owing to intrinsic instability of the C3 component. C3 contains an internal thioesther bond that undergoes spontaneous hydrolysis, increasing susceptibility of C3 to cleavage to form $\mathrm{C} 3 \mathrm{~b}$. The exposed carbonyl group of $\mathrm{C} 3 \mathrm{~b}$ forms a bond with neighboring nucleophiles. The properties of the surface to which $\mathrm{C} 3 \mathrm{~b}$ binds, among other factors, determines whether $\mathrm{C} 3 \mathrm{~b}$ will form a catalytic complex with another protein, generating downstream effectors, or whether it will be degraded to a catalytically inactive fragment, $\mathrm{C} 3 \mathrm{~d}$. Although $\mathrm{C} 3 \mathrm{~d}$ cannot further activate complement, it can bind to complement receptor 2 (CR2) expressed mainly on follicular DCs (FDCs) and B cells (4). Interaction of C3d with CR2 enhances antibody responses by reducing the threshold for B cell activation (5) and facilitates retention and internalization of antigens (6). For example, conjugation of 3 molecules of C3d to antigens decreases by $1 \times 10^{4}$ the amount of antigen needed to elicit antibody responses. 
We made the unanticipated observation that the presence of $\mathrm{C} 3 \mathrm{~d}$ as a free peptide in living tumor cells or in a killed tumor cell vaccine vitiates restraints on immune surveillance, allowing rapid and robust control of lethal cancers in mice. We show that this function of C3d is completely independent of B cells or mature FDCs and, hence, represents a heretofore unrecognized function of C3d in the governance of protective cellular immunity.

\section{Results}

Our observations emerged in the course of testing a vaccine designed to evoke broadly neutralizing antibodies against HIV. Because antigen with covalently attached C3d profoundly decreases the threshold for antibody responses (5), we developed DNA constructs that encoded murine C3d attached to a viral antigen, as previously described $(7,8)$. To test expression and immunogenicity, the constructs were expressed in 18-81 pre-B lymphoma cells originated by Abelson transformation $(9,10)$, and transfected lymphoma cells were introduced into isogeneic mice. Protective immunity was readily discerned, as transfected lymphoma cells generated slowly growing tumors while mock transfected lymphoma cells generated rapidly growing tumors that invaded spleen and muscle, causing death within 28 days (Figure $1, \mathrm{~A}-\mathrm{C}$, and Supplemental Figure 1, A-D; supplemental material available online with this article; https://doi.org/10.1172/jci. insight.90201DS1). What we did not anticipate, however, was that control lymphoma cells expressing only C3d as a free polypeptide and no viral antigen grew slower than mock-transfected lymphoma cells in isogeneic mice $(P<0.0001)$, and $25 \%$ of the lymphomas spontaneously resolved (Figure $1, \mathrm{~A}-\mathrm{C})$. The impact of free C3d was not limited to lymphomas, as expression of C3d in B16 melanoma cells also slowed tumor growth and prolonged survival of mice in which the cells were introduced (Figure 1D). C3d, expressed as a free peptide, thus appeared to evoke resistance to tumors.

Resistance conferred by $\mathrm{C} 3 \mathrm{~d}$ depended entirely on adaptive immunity and did not have any direct impact on tumor growth, as $\mathrm{C} 3 \mathrm{~d}^{+}$and $\mathrm{C} 3 \mathrm{~d}^{-}$lymphomas grew and caused death at the same rate in RAG-deficient mice (Figure 1E). Also, C3d itself did not serve as a target, as mixtures of $\mathrm{C} 3 \mathrm{~d}^{+}$and $\mathrm{C} 3 \mathrm{~d}^{-}$tumor cells in ratios as low as 1:100 elicited resistance (Figure $1 \mathrm{~F}$ ). Resistance did require the native $\mathrm{C} 3 \mathrm{~d}$ structure, as it was vitiated by administration of CR2-Ig, which binds to and blocks C3d interactions with CR2 (11) (Table 1).

Unlike the known actions of $\mathrm{C} 3 \mathrm{~d}$ on $\mathrm{B}$ cell responses $(5,12)$, the protection against tumors did not depend on B cells or FDCs, as protection was fully manifest in B cell and Ig-deficient $\mathrm{JH}^{-/-} \kappa^{-/-}$mice, which lack mature FDCs, as well (13) (Figure 1G). Protection depended on T cells, since a single infusion of antiCD4 and anti-CD8 antibodies suppressed protection (Supplemental Figure 1E) and since C3d expression by lymphoma cells markedly augmented the number of tumor-infiltrating CD8 $8^{+}$lymphocytes (Figure $1 \mathrm{H}$ ). Thus, the presence of C3d polypeptide in even a small fraction of tumor cells hastened and amplified cell-mediated immune surveillance directed against endogenous tumor antigens.

To confirm that free C $3 \mathrm{~d}$ promoted adaptive immunity, we tested the impact of free C3d on the efficacy of killed tumor cell vaccines. As Figure $2 \mathrm{~A}$ shows, vaccination with killed $\mathrm{C} \mathrm{d}^{+}$lymphoma cells protected mice from living lymphoma cells injected 35 days later, regardless of whether the living tumor cells expressed C3d. Vaccination with killed C3 $\mathrm{d}^{-}$lymphoma cells (Figure 2B) conferred significantly less protection against living $\mathrm{C} 3 \mathrm{~d}^{-}$lymphomas and provided no incremental protection against living $\mathrm{C} 3 \mathrm{~d}^{+}$tumor cells. C3d also promoted adaptive immune surveillance of melanoma (Figure 2, C-F). Thus, mice vaccinated once with killed $\mathrm{C} 3 \mathrm{~d}^{+}$melanoma cells and later injected with living melanoma cells not expressing C3d lived longer and had, on average, 5.7-fold smaller tumors than nonvaccinated mice and 3 -fold smaller tumors than mice vaccinated with $\mathrm{C} 3 \mathrm{~d}^{-}$melanoma cells (Figure 2, D-F). These results confirm that $\mathrm{C} 3 \mathrm{~d}$, as a free polypeptide, promotes protective immunity directed at endogenous tumor antigens and not against $\mathrm{C} 3 \mathrm{~d}$.

A function for free $\mathrm{C} 3 \mathrm{~d}$ in adaptive immunity, and particularly cell-mediated immunity, has not been previously reported. However, T cells have been reported to express CR2, the cognate receptor for C3d (14-17). We therefore wondered whether C3d might govern immune surveillance by interacting with CR2. At baseline, $<5 \%$ of Tregs in the spleens of naive mice expressed CR2 (Supplemental Figure 2A), consistent with some reports (18). After injection of $\mathrm{C} 3 \mathrm{~d}^{+}$lymphoma cells, Treg exhibited a striking increase in expression of CR2 mRNA ( $P=0.01$ ) (Figure 3A and Supplemental Figure 2, A-D). However, the frequency of Treg CR2 ${ }^{+}$cells, as measured by FACS, was decreased by almost 2-fold within $C 3 \mathrm{~d}^{+}$lymphomas, relative to that frequency in $\mathrm{C} 3 \mathrm{~d}^{-}$lymphomas $(P=0.02)$ (Figure $3, \mathrm{~B}$ and $\mathrm{F}$ ), suggesting selective loss of CR2 ${ }^{+}$Treg in $\mathrm{C} \mathrm{d}^{+}$lymphomas. Expression of CR2 on Treg anticipated depletion, as CR2 ${ }^{+}$Tregs in C3 $\mathrm{d}^{+}$lymphomas 
A Lymphoma in BALB/c mice

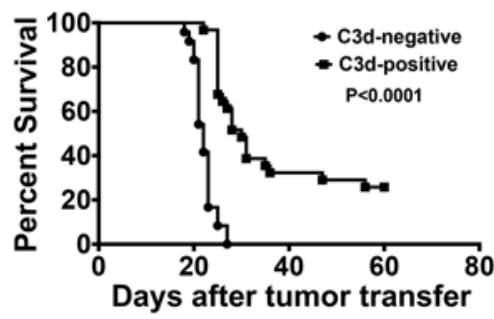

D Melanoma in C57BL/6 mice

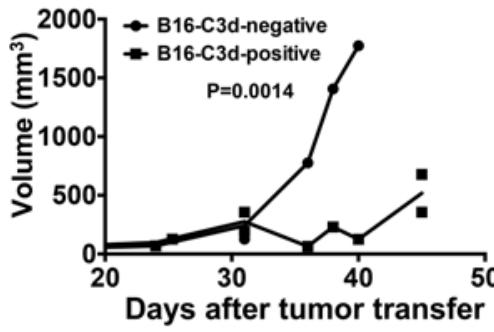

F

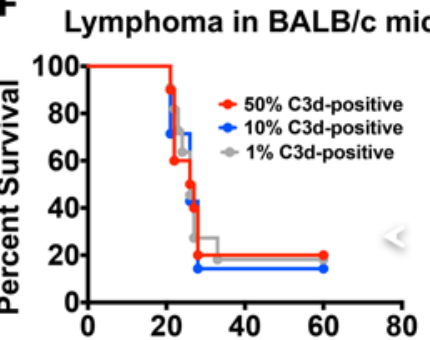

Days after tumor transfer
B Lymphoma in BALB/c mice

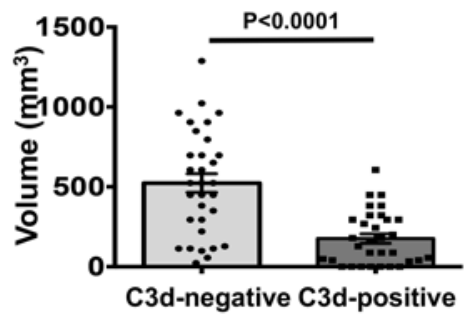

E

Lymphoma in RAG-deficient mice

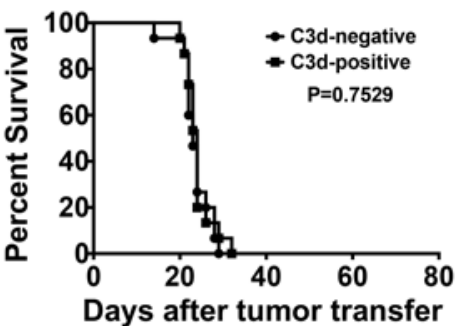

G

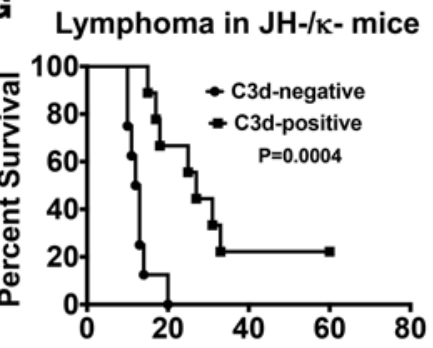

Days after tumor transfer
C
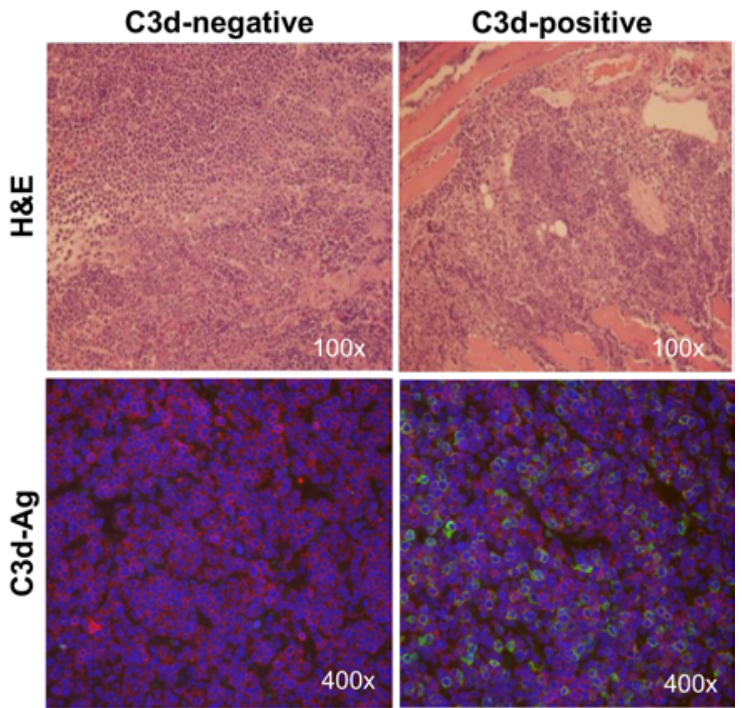

H

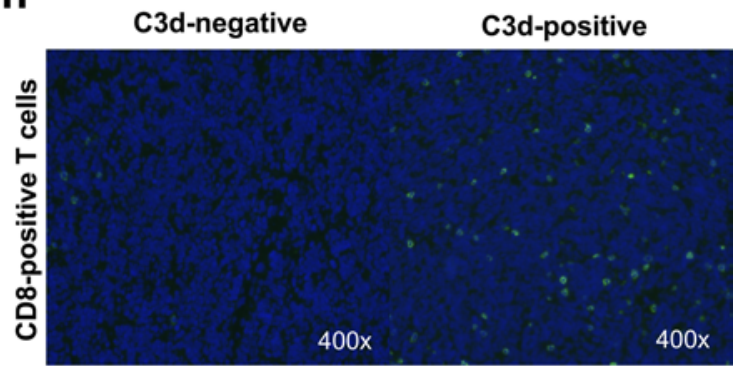

Figure 1. Free C3d in tumor cells enhances resistance of mice to tumors by promoting adaptive immunity. (A) Survival of BALB/C mice challenged with 5 $\times 10^{3}$ isogenic lymphoma cells expressing $(n=31)$ or not expressing $(n=24)$ free murine C3d. (B) Lymphoma tumor volumes 10 days after injection of $1 \times 10^{7}$

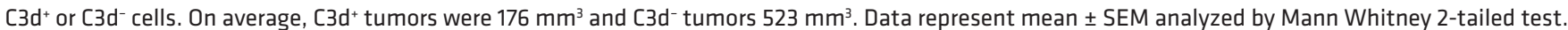

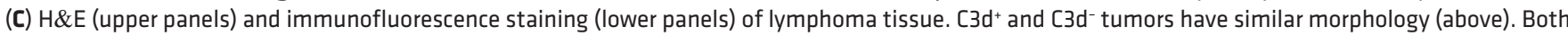
are recognized by antibodies against B220 (red; below), but only the transgenic C3d+ lymphoma stains with antibodies against an ENV fusion construct used to detect expression of C $3 \mathrm{~d}$ (green; below). Images are representative of tissues from 5 mice analyzed per condition and a minimum of 3 images/ mouse. (D) Melanoma tumor volumes at various times after s.c. injection of $4 \times 10^{4}$ C3 d B16 $(n=10)$, or $4 \times 10^{4}$ C3d- $(n=9)$ melanoma cells in syngeneic mice. (E) Survival of recombinase activating gene 2-deficient (RAG-2-deficient) mice injected with $5 \times 10^{3}$ isogenic $C 3 \mathrm{~d}^{+}(n=15)$ or C3 $\mathrm{d}^{-}(n=15)$ lymphoma cells. (F) Survival of mice injected with $5 \times 10^{3}$ lymphoma cells of which $1 \%-50 \%$ were $C 3 \mathrm{~d}^{+}$. (C) Survival of B cell-deficient $\left(J \mathrm{H}^{-/-} \mathrm{K}^{-/-}\right)$mice challenged with

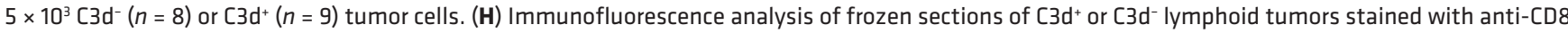
antibodies (green). Each panel is representative of at least 3 different tumors. CD8 ${ }^{+} T$ cells were enumerated by flow cytometry, and results are shown on Figure 3H. All survival curves are Kaplan-Meier plots, and differences between curves were analyzed by the log rank Mantel-Cox test.

expressed caspase 3 and caspase 7 (Figure 3, C and G, and Supplemental Figure 2B) more frequently than CR2 ${ }^{+}$Tregs in $\mathrm{C}^{2} \mathrm{~d}^{-}$lymphomas $(P=0.0003)$. Consistent with the possibility that C3d interactions with CR2-depleted Tregs, C3 $\mathrm{d}^{+}$lymphomas contained few Tregs, while C3 $\mathrm{d}^{-}$lymphomas contained many $(P<$ 0.0001) (Figure 3, D and E). Although CD8 ${ }^{+} \mathrm{T}$ cells did not express CR2 (not shown), CD8 ${ }^{+} \mathrm{T}$ cells were more frequent in $\mathrm{C} 3 \mathrm{~d}^{+}$lymphomas and rare on $\mathrm{C} 3 \mathrm{~d}^{-}$lymphomas (Figure $1 \mathrm{H}$ ), and they were more frequently apoptotic in $\mathrm{C} \mathrm{d}^{-}$lymphomas (Figure $3, \mathrm{H}$ and $\mathrm{I}$ ), suggesting that $\mathrm{C} 3 \mathrm{~d}$ expressed by tumors might prevent apoptosis of $\mathrm{CD}^{+}$intratumor lymphocytes.

Next, we asked whether vaccination with $\mathrm{C} 3 \mathrm{~d}^{+}$-killed melanoma cells promoted apoptosis of Treg following tumor challenge. Figure $4 \mathrm{~A}$ shows that vaccination with $\mathrm{C}^{2} \mathrm{~d}^{+}$-killed melanoma cells promoted apoptosis of Tregs in the draining lymph nodes, while vaccination with C3d-killed melanoma cells did not $(P=0.02)$. As observed in the lymphoma model, $\mathrm{C} 3 \mathrm{~d}^{+}$tumors had more frequent apoptotic Tregs than C $3 \mathrm{~d}^{-}$tumors $(P=0.03) 14$ days after tumor challenge (Figure $\left.4 \mathrm{~A}\right)$. Vaccination with $\mathrm{C} 3 \mathrm{~d}^{+}$-killed melanoma cells reduced, by 6 -fold, the size of $\mathrm{C} 3 \mathrm{~d}^{-}$tumors 14 days after tumor challenge and by 5 -fold compared 
Table 1. Analysis of survival of mice recipients of tumors containing varying proportions of $\mathrm{C} \mathrm{d}^{+}$cells by Kaplan-Meier plots, and differences between curves were analyzed by the log rank Mantel-Cox test

\begin{tabular}{|c|c|c|c|c|c|}
\hline$\%$ C3 $\mathrm{d}^{+}$tumor cells & $0 \%$ & $1 \%$ & $10 \%$ & $50 \%$ & $100 \%$ \\
\hline \% Survival & $\begin{array}{c}0 \% \\
(n=24)\end{array}$ & $\begin{array}{l}18.2 \% \\
(n=11)\end{array}$ & $\begin{array}{l}14.3 \% \\
(n=7)\end{array}$ & $\begin{array}{c}20 \% \\
(n=10)\end{array}$ & $\begin{array}{l}25.8 \% \\
(n=31)\end{array}$ \\
\hline
\end{tabular}

with vaccination with $\mathrm{C}^{-} \mathrm{d}^{-}$melanoma cells (Figure $4 \mathrm{~B}$ ). In contrast, $\mathrm{C} 3 \mathrm{~d}^{-}$melanoma vaccination did not reduce $\mathrm{B} 16$ tumor growth, as the average tumor size after vaccination was almost identical to the average tumor size in nonvaccinated mice (Figure 4B). Figure 4, A and B, also show that the frequency of apoptotic Tregs varies reciprocally with tumor size: the smaller the tumors, the more frequent apoptotic Tregs are within each group. Supplemental Figure 3 shows that expression of C3d by melanoma cells yielded smaller tumors with larger necrotic areas, greater infiltration by $\mathrm{CD}^{+}$and $\mathrm{CD} 8^{+}$lymphocytes and fewer Foxp3 $3^{+}$ cells (Supplemental Figure 3, B, F, J, and N) compared with C3d- melanomas (Supplemental Figure 3, A, E, I, and M). Supplemental Figure 3 shows that vaccination with $C 3 \mathrm{~d}^{+}$-killed melanoma cells was more effective at causing involution of $\mathrm{C} \mathrm{d}^{-}$melanomas (generated by injection of tumor cells 35 days after vaccination), at promoting infiltration of $\mathrm{CD}^{+}$and $\mathrm{CD}^{+}$lymphocytes, and at decreasing Foxp3 ${ }^{+}$cells (Supplemental Figure 3, D, H, L, and P) than vaccination with C3d-killed melanoma cells (Supplemental Figure 3, C, G, K, and O).

As expected, both $\mathrm{C} 3 \mathrm{~d}^{+}$and $\mathrm{C} 3 \mathrm{~d}^{-}$vaccines decreased the frequency of CR2 ${ }^{+}$Tregs in lymph nodes draining melanomas compared with the frequencies in nonvaccinated mice (Figure 4, C and D). Treg CR2 expression was independent of vaccination, since unvaccinated mice expressed the highest frequency of $\mathrm{CR}^{+}$Tregs, and Treg CR2 expression increased with the size of the tumor (Figure 4, C and D). In mice given $\mathrm{C} 3 \mathrm{~d}^{-}$tumor vaccines, the frequency of CR2 $2^{+}$Tregs was independent of the size of the tumor (Figure 4D), while in mice given $\mathrm{C} 3 \mathrm{~d}^{+}$vaccines, the frequency of $\mathrm{CR} 2^{+}$Tregs and tumor size were decreased (Figure 4D). Figure $4 \mathrm{E}$ shows that $\mathrm{C} 3 \mathrm{~d}^{+}$vaccines, but not $\mathrm{C} 3 \mathrm{~d}^{-}$vaccines, reduced the frequency of Tregs in the tumor-draining lymph nodes, suggesting $\mathrm{C} 3 \mathrm{~d}^{+}$vaccines selectively promote apoptosis of CR $2^{+}$Tregs, in agreement with results shown above. Consistent with this concept, tumor size increased in parallel with the frequency of Tregs (Figure 4F).

Interaction of C3d with CR2 had another potentially important function. Increased expression of CR2 correlated with dramatically decreased expression of PD-1 (Figure 5, A and B), which silences effector T cells by engaging PD ligand-1 (PD-L1) (19). Consistent with an impact of C3d on this pathway, C3d ${ }^{+}$ tumors had increased frequencies of infiltrating $\mathrm{T}$ cells producing perforin, TNF $\alpha$, and IFN $\gamma$ (Figure 5, C and D), and $\mathrm{T}$ cells isolated from $\mathrm{C} 3 \mathrm{~d}^{+}$tumors exhibited increased cytotoxicity against $\mathrm{C} 3 \mathrm{~d}^{-}$tumor cells (Supplemental Figure 2E).

We next asked whether the free C $3 \mathrm{~d}$ polypeptide exerts a discernable impact on responses of isolated $\mathrm{T}$ cells. Addition of $\mathrm{C} 3 \mathrm{~d}$ to naive $\mathrm{CD} 4^{+} \mathrm{T}$ cells caused a modest increase in proliferation, and this increase was greatly potentiated by anti-CR2 antibodies with agonist properties (20) (Supplemental Figures 4, A and B). C3d and anti-CR2 also inhibited Treg differentiation (Supplemental Figure 4A). These

Table 2. Analysis of survival of mice recipients of C3d+ or C3d- tumors injected or not with CR2-lg to block C3d

\begin{tabular}{|c|c|c|c|c|}
\hline & C3 $d^{+}$ & C3d $\mathrm{d}^{+}+$CR2Ig & C3d- & $\mathrm{C} \mathrm{d}^{-}+$CR2Ig \\
\hline$\%$ Survival after 15 days & $60 \%(n=5)$ & $0 \%(n=5)$ & $0 \%(n=5)$ & $0 \%(n=5)$ \\
\hline$P$ value (Mantel-Cox test) & & $P=0.001$ & & $P=0.119$ \\
\hline
\end{tabular}


A

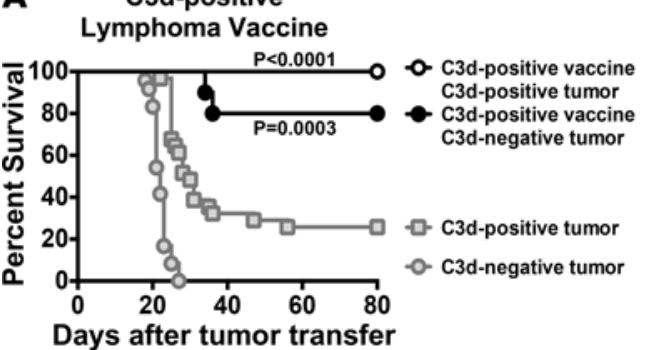

B

C3d-negative

Lymphoma Vaccine

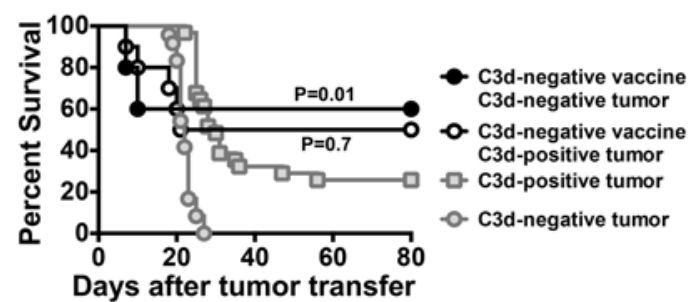

C

C3d-positive or C3d-negative Melanoma Vaccine

Non-Vaccinated C3d-negative vaccine

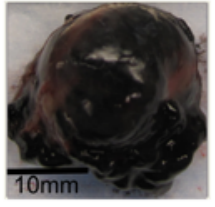

Day 21

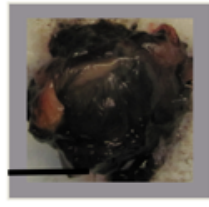

Day 18

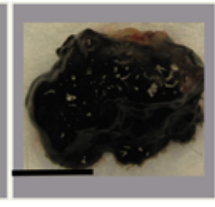

Day 21

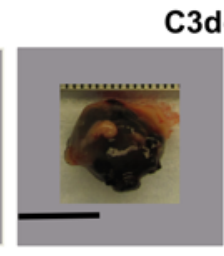

Day 18 C3d-positive vaccine

D

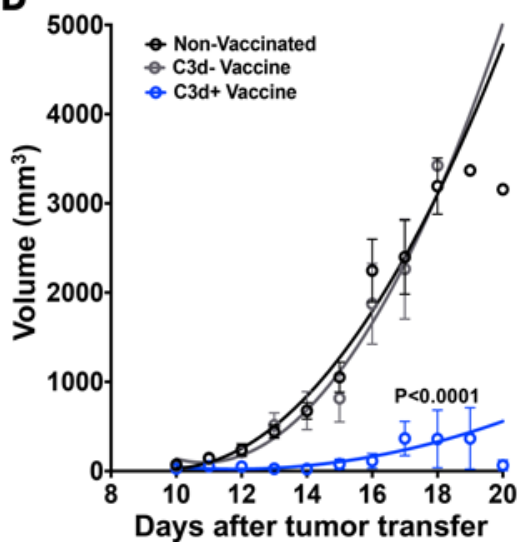

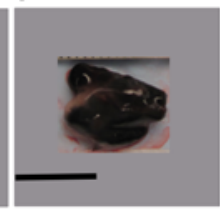

Day 21

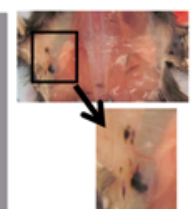

Day 21
$\mathbf{E}$

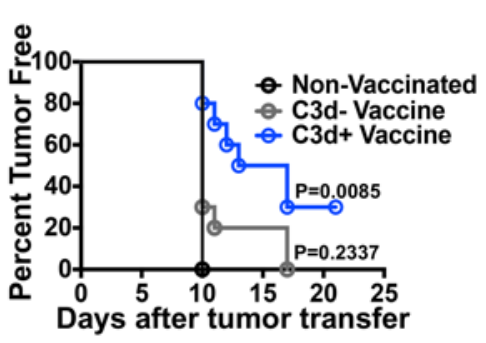

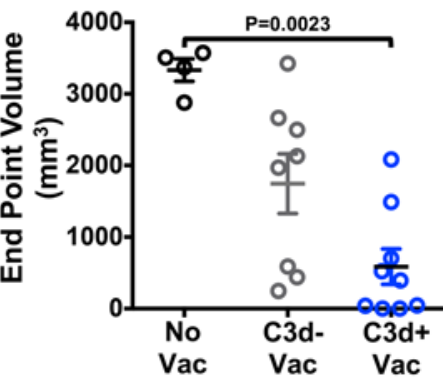

Figure 2. Adaptive immunity evoked by vaccination with killed $C 3 \mathrm{~d}^{+}$tumor cells protects against lymphoma and melanoma. Mice were vaccinated

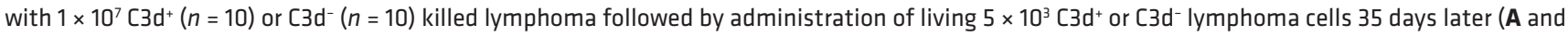

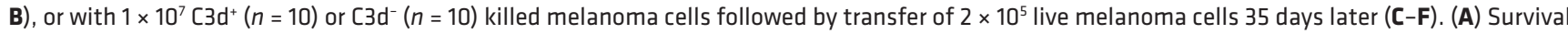

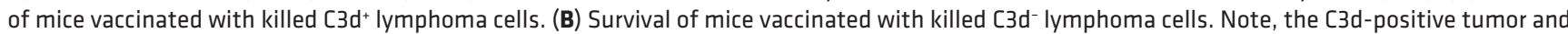
C3d-negative tumor groups in (A) and (B) are the same data as presented in Figure 1A. The data were not collected contemporaneously as the other groups in (A) and (B), but are shown here for reference. (C) Photographs of C3d- melanoma tumors excised at indicated days after tumor inoculation in mice vaccinated with $\mathrm{C3}^{+}$or $C 3 \mathrm{~d}^{-}$irradiated melanoma cells. Shown also is a photograph of an incipient tumor growing s.c. (inset) in mice vaccinated

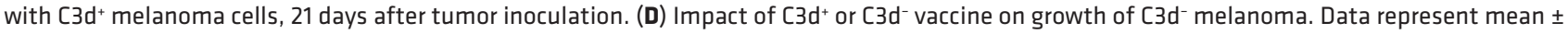

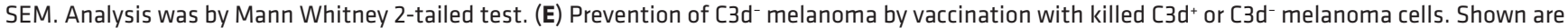
Kaplan-Meier plots, and differences between curves were analyzed by the log rank Mantel-Cox test. (F) Impact of vaccination on growth of $C 3 \mathrm{~d}^{-}$melanoma estimated by tumor size at death (sacrifice) or at 21 days in mice that were alive at 21 days. All nonvaccinated mice and 8 of 10 mice vaccinated with C3d- melanoma died or were sacrificed at 18 or 19 days for humane reasons. Four of 10 C $3 \mathrm{~d}^{+}$-vaccinated mice either had no apparent tumors or smaller tumors at sacrifice (21 days). Data represent mean \pm SEM. Analysis was by Mann Whitney 2-tailed test.

results appear to represent at least some facets of the impact of C3d on immune surveillance because mice given anti-CR2 antibodies resisted $\mathrm{C} 3 \mathrm{~d}^{-}$tumors to the same extent as mice given $\mathrm{C} 3 \mathrm{~d}^{+}$tumor cells but no antibody (Figure 5E and Table 2).

\section{Discussion}

Our findings, to our knowledge, reveal hitherto unrecognized involvement of the complement system in regulation of immune surveillance. Complement is well known to amplify B cell responses, particularly against C3d-tagged antigen, and to facilitate $\mathrm{T}$ cell activation by activating antigen-presenting cells $(21,22)$. However, a function of free C3d in the governance of cellular immunity to endogenous tumor antigens has not been reported. The dramatic impact of therapies directed at immune checkpoints 
A

CR2 expression by regulatory $T$ cells

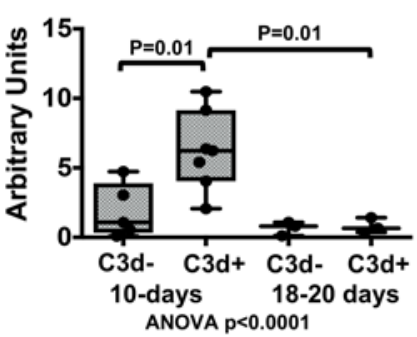

E
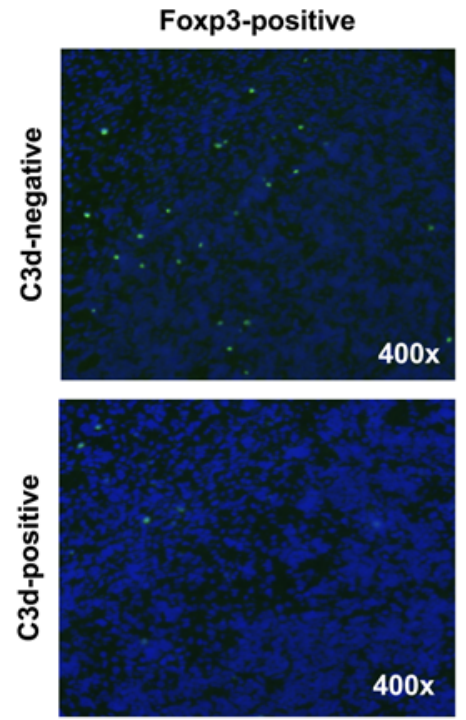

B

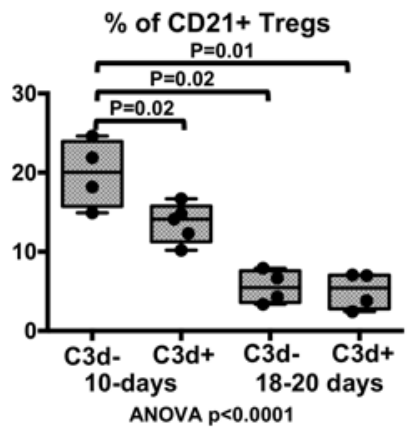

$\mathbf{F}$

CD21+ T regulatory cells

C3d-negative

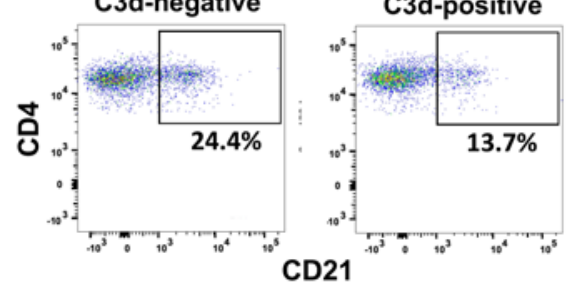

H

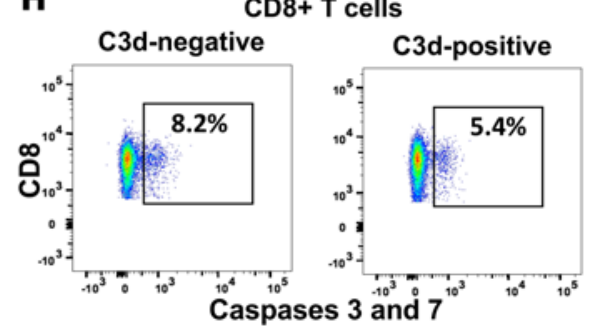

D $\%$ of apoptotic CD21+ Tregs $\%$ Tregs / CD4+ T cells
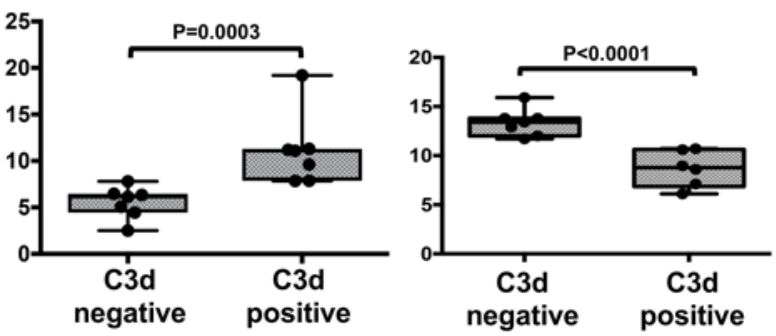

G

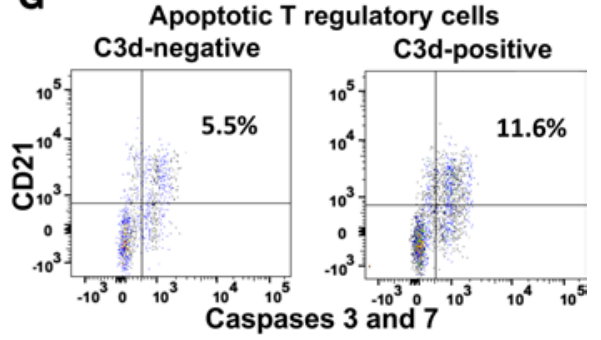

I $\%$ of apoptotic CD8+ T cells

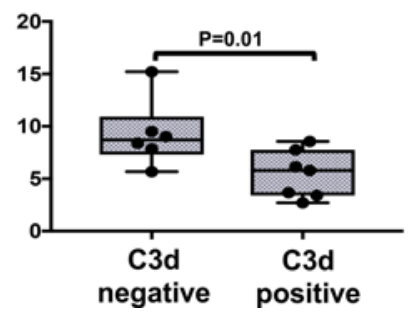

Figure 3. Impact of C3d on expression of CR2 (CD21) by Tregs and on apoptosis of Tregs and CD8+ cells in lymphomas. (A) CR2 expression by Tregs after introduction of $C 3 \mathrm{~d}^{+}$or $C 3 \mathrm{~d}^{-}$lymphoma cells. Expression was determined by qPCR relative to GAPDH; CR2 expression by naive Tregs was subtracted. Graphs reflect analysis of 3-7 mice per time point, in triplicate. (B and F) Frequency of CD21+ Tregs determined by flow cytometry analysis of splenocytes.

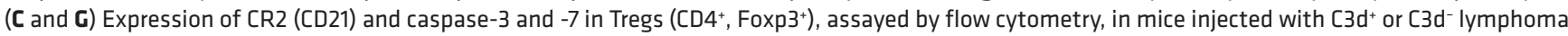
cells 10 days before analysis. The graphs depict frequencies of apoptotic Tregs in tumor-recipient mice. (D) Frequency of Tregs (CD4 ${ }^{+}$, Foxp3 $3^{+}$) determined

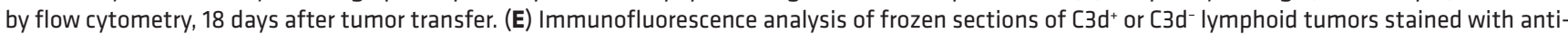
Foxp3 antibodies (green). Each panel is representative of at least 3 different tumors. (H and I) Expression of caspase-3 and -7 in CD $8^{+} T$ cells assayed by

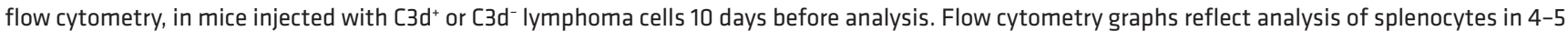
mice per condition. Boxes represent distribution of data between the 25th and the 75th percentiles. The mean is indicated by a horizontal line, and whiskers represent maximum and minimum values. Statistical analysis in $\mathbf{A}$ and $\mathbf{B}$ was by the Kruskal Wallis test followed by Dunn's multiple comparison test. Analysis in $\mathbf{C}, \mathbf{D}$, and I was by the Mann Whitney 2-tailed test.

suggests that such governance, rather than initiation of immunity, limits immune surveillance of cancer - and perhaps more generally. Work in complement-deficient mice indicates that $\mathrm{C} 3$ acting in part on antigen-presenting cells promotes the priming of $\mathrm{T}$ cells at initiation of cellular immunity $(23,24)$. However, the actions of free $\mathrm{C} 3 \mathrm{~d}$ we report are exerted later, at regulatory checkpoints in WT mice, which manifestly fail to exert effective immune surveillance of tumors. Thus, we show for the first time to our knowledge that complement, particularly C3d, may be a key factor in determining whether immune surveillance or immune suppression prevails.

The complement system has manifold functions that facilitate the phagocytosis, killing, and disposal of microorganisms and damaged or foreign cells. The complement system also regulates the physiology of normal cells to circumscribe sites of injury and infection $(23,25)$ and to recruit adaptive immunity, as mentioned above (5). Whether complement provides an intrinsic defense against cancer (26), as long supposed, or promotes a microenvironment that nurtures the inception and progression of cancer (27-32), as recently proposed, or both is yet undecided; the net impact might well vary from case to case. Similarly, the products 
A

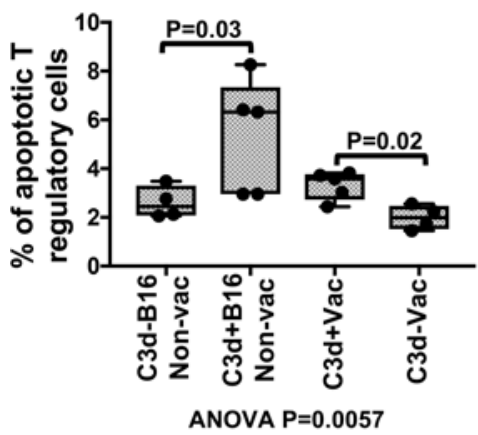

\section{C}

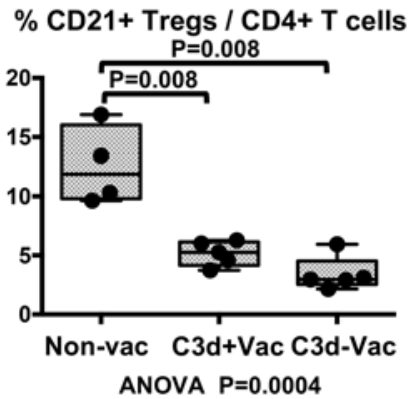

E

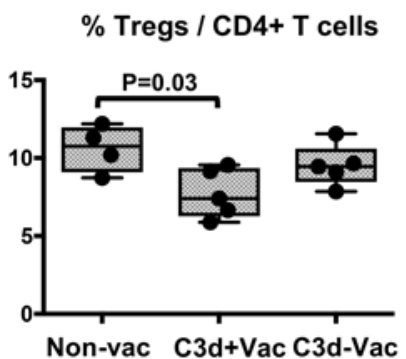

B

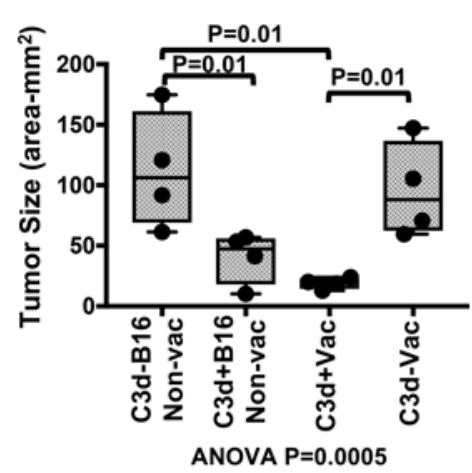

D $\frac{\omega}{\bar{d}}$

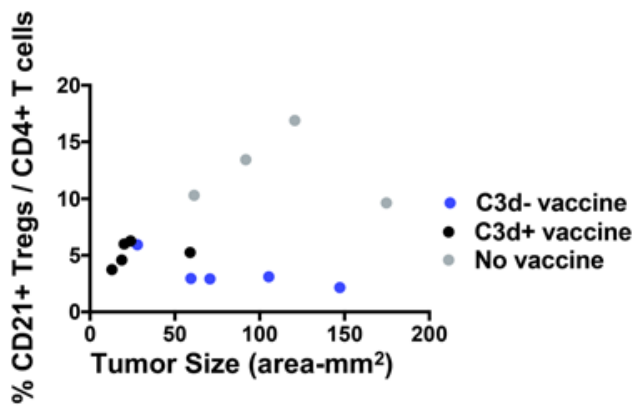

$\mathbf{F}$

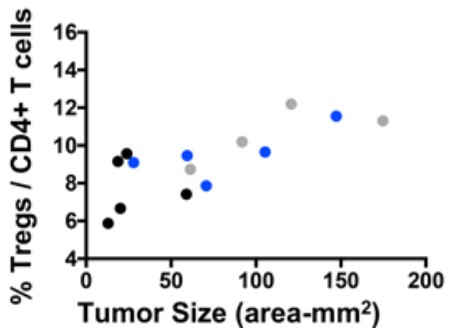

Figure 4. Impact of C3d on CD21 expression by Tregs, on apoptosis of Tregs, and on Treg frequencies following vaccination against melanoma. Graphs reflect analysis of lymphocytes obtained from tumor-draining lymph nodes of 4-5 mice/group 14 days after tumor transfer. Mice were vaccinated by injection of $1 \times 10^{7}$ killed melanoma cells 35 days prior to transfer of $2 \times 10^{5}$ live tumor cells. Vaccinated mice were challenged with $\mathrm{C3d}^{-}$ tumor cells (expressing empty vector marker). (A) Frequency of apoptotic Treg (CD4 ${ }^{+}$, Foxp3 $^{+}$, caspase $3^{+}$and $-6^{+} / \mathrm{CD}^{+}$, Foxp $3^{+}$cells $\times 100$ ) in nonvaccinated or vaccinated mice determined by flow cytometry. (B) Tumor size (measured as areas) in the mice corresponding to the Iymphocyte analysis. (C) Frequency of CD21+ Tregs (CD4+, CD21+, Foxp3 $3^{+} / \mathrm{CD}^{+} \times$100). (D) Plot compares the frequencies of $\mathrm{CD} 21^{+}$Tregs with the respective tumor sizes. Each dot represents one mouse. (E) Frequency of Tregs $\left(\mathrm{CD}^{+}\right.$, Foxp3 $\left.3^{+} / \mathrm{CD}^{+} \times 100\right)$ determined by flow cytometry. (F) Plot compares the frequencies of Tregs with the respective tumor sizes. Each dot represents one mouse. Boxes in graphs represent distribution of data between the 25 th and the 75 th percentiles. The mean is indicated by a horizontal line, and whiskers represent maximum and minimum values. Statistical analysis in A, B, C, and $\mathbf{E}$ was by the Kruskal Wallis test followed by Dunn's multiple comparison test.

of complement activation and the impact of complement on malignant cells might promote or regulate adaptive immune responses of $\mathrm{B}$ cells and $\mathrm{T}$ cells with uncertain net impact on resistance to cancer. However, our experiments reveal a clear, unidirectional protective impact of free C $3 \mathrm{~d}$ in tumor cells that might be exploited to some advantage in advancing the treatment or prophylaxis of cancer. However, since we did not modify the complement system of the mice we used, the impact of C3d should not be taken as favoring or opposing the potential involvement of the complement system in the spontaneous development of or natural resistance to cancer.

The protection against $C 3 \mathrm{~d}^{-}$tumor cells conferred by vaccination with killed $C 3 \mathrm{~d}^{+}$tumor cells would seem to exclude the possibility that efficacy was owed to immunity targeting C3d-derived peptides. However, Knopf et al. (33) and De Groot et al. (34) propose that presentation of C3d-derived peptides by antigen-presenting cells in other systems might stimulate autoreactive $\mathrm{T}$ cells. We cannot exclude entirely the possibility that protective immunity evoked by $\mathrm{C} 3 \mathrm{~d}^{+}$tumor cells in our experiments reflected cross-reactivity with "normal" peptides and, hence, autoimmunity rather than tumor-specific immunity. However, in experiments using a $1 \times 10^{4}$-fold range of doses of $\mathrm{C} \mathrm{d}^{+}$tumor cells, we never observed evidence of autoimmune disease, and only tumor appeared to limit vitality. We interpret this lack of toxicity to suggest that, predominantly, immunity was directly against tumor antigens and consider such selectivity to be potentially a major advantage of this approach. Since systemic suppression of checkpoint controls engender significant toxicity, we speculate that our approach might have averted toxicity in part because C3d was associated with tumor cells and was not introduced systemically. If that is correct, then toxicity of other approaches might be similarly decreased if suppressive agents can be delivered with tumor cells.

Although our findings suggest free C3d predominantly disrupts immune checkpoint suppression, we cannot exclude the possibility of an impact on $\mathrm{T}$ cell priming, perhaps shifting ensuing responses away 
A

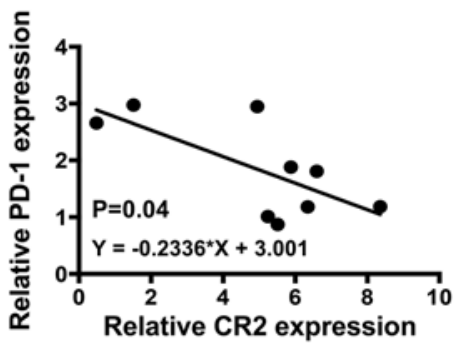

C

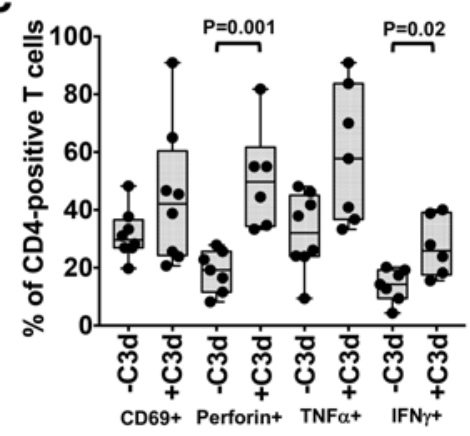

B

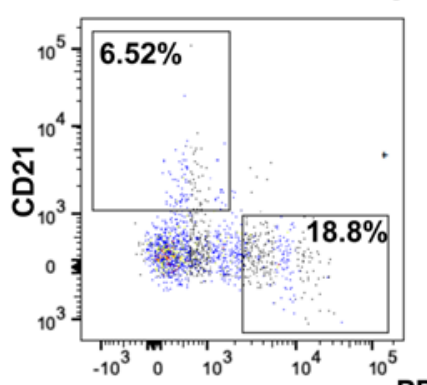

T regulatory cells

D

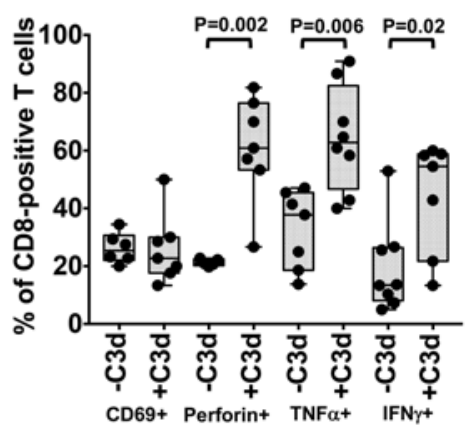

E

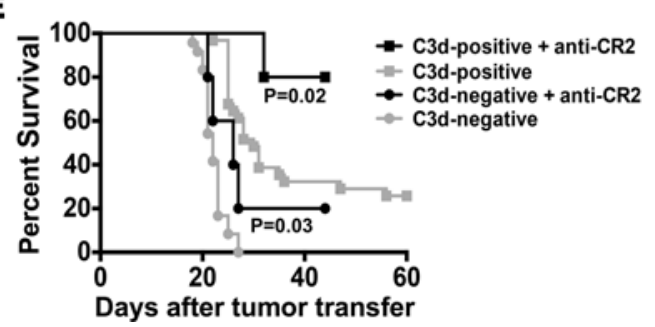

Figure 5. C3d modifies antitumor T cell functions. (A) CR2 and PD-1 expression measured by $q P C R$ on Tregs. Expression of CR2 and PD-1 were relative to that of CAPDH. (B) Flow cytometry analysis of lymphocytes obtained from the spleen of mice 10 days after injection of $5 \times 10^{3}$ lymphoma cells. Figure shows reciprocal expression of CD21 and PD-1 by Tregs $\left(\mathrm{CD4}^{+}\right.$, $\left.\mathrm{Foxp}^{+}\right)$. (C and $\left.\mathbf{D}\right)$ Figure shows the percent (\%) of $\mathrm{CD}^{+}(\mathbf{C})$ or $\mathrm{CD} 8^{+}$(D) T cells isolated from the spleen of recipients of $\mathrm{C} \mathrm{d}^{+}$or $\mathrm{C} 3 \mathrm{~d}^{-}$tumors that express perforin, $\mathrm{TNF} \alpha$, and IFN $\gamma, 3.5$ hours after culture on anti-CD3- and antiCD2-coated plates. Boxes in graphs represent distribution of data between the 25 th and the 75 th percentiles. The mean is indicated by a horizontal line, and whiskers represent maximum and minimum values. Statistical analysis was by the

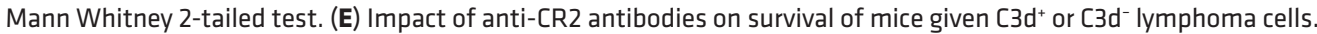
Anti-CD21/CD35 (7C6) antibodies were administered at the same time as tumor cells. Figure represents Kaplan-Meier plots obtained with at least 5 mice per condition, and differences between curves were analyzed by the log rank Mantel-Cox test. Note, the C3d-positive tumor and C3d-negative tumor groups in (E) are the same data as presented in Figure $1 \mathrm{~A}$. The data were not collected contemporaneously as the other groups in (E), but are shown here for reference.

from suppression. However, the absence of generalized lymphoproliferation and absence of notable differences in sizes of draining lymph nodes between mice vaccinated with $C 3 \mathrm{~d}^{+}$versus $C 3 \mathrm{~d}^{-}$tumor cells suggests any impact on priming was limited.

Our observations suggest $\mathrm{C} 3 \mathrm{~d}$ might prove advantageous for immunotherapies and vaccines. Association of $\mathrm{C} 3 \mathrm{~d}$ with tumor cells or tumor cell vaccines might allow $\mathrm{T}$ cells specific for tumor antigens to generate protective immunity, leaving $\mathrm{T}$ cells specific for pleiotropic targets subject to regulation.

\section{Methods}

Mice, tumor cell lines, and tumor formation. Female BALB/c $\left(\mathrm{H}-2^{\mathrm{d}}\right), \mathrm{Rag}-2^{-/-}\left(\mathrm{H}-2^{\mathrm{d}}\right)$, and C57BL/6J $\left(\mathrm{H}-2^{\mathrm{b}}\right)$ mice were purchased from the Jackson Laboratory (JAX). BALB/c JH${ }^{-1-} \mathrm{K}^{--}\left(\mathrm{H}-2^{\mathrm{d}}\right)$ mice lack mature B cells and Ig owed to gene-targeted deletion of the $\mathrm{JH}$ and $\mathrm{J} \kappa$ segments, and they were bred at the University of Michigan. At the time of vaccination or tumor transfer, mice were between 6 and 10 weeks of age and were sex matched and age matched in each experiment. Lymphoma cells were the murine pre-B cell 18-81 lymphoma, subclone 
A3.43 $(35,36)$. Lymphoid tumors were induced by i.p. adoptive transfer of $5 \times 10^{3}$ or $1 \times 10^{7}$ cells, as indicated in the text, of either pre-B cell lymphoma cells expressing C3d or not. Whenever tumor diameter exceeded 10 $\mathrm{mm}$, or whenever there were signs of excessive morbidity, animals were euthanized and the event recorded as death from tumor burden. Melanoma tumors were obtained by s.c. injection of $4 \times 10^{4}$ or $5 \times 10^{5} \mathrm{~B} 16$-F0 cells, purchased from ATCC (catalog CRL-6322), expressing C3d or not, in the flank region. Tumor volumes were determined by measuring 2 diameters of the dissected tumors, using electronic calipers, calculating the average radius and converting to areas or spherical volumes. Tumors cells purchased from ATCC were free of mycoplasma and free of aerobic or anaerobic bacterial contamination, as per the company's certificate of analysis.

C3d expression vectors. To generate the vector-encoding expression of only the C3d gene to transfect lymphoma cells, the pcDNA3.1 vector containing the E $\mu$ enhancers, $\lambda_{1}$ promoter, and HIV-ENV-C3d vector was modified (7). Specifically, the completed vector was partially digested with Nhe1 and fully digested with BAM H1. The DNA was then separated by gel electrophoresis, and the $10.7-\mathrm{Kb}$ band representing the pcDNA 3.1 vector without the gp140 sequence - but with the E $\mu$ enhancer, $\lambda_{1}$ promoter, and C3d DNA - was purified from the gel. The ends of this DNA were then filled in with Klenow (Thermo Fisher Scientific) and ligated together to form a vector that would drive expression of only $\mathrm{C} 3 \mathrm{~d}$ by the B cell regulatory elements. The E $\mu$ was a 678 -bp sequence (NCBI M12827 position [pos] 7-68, and the $\lambda_{1} p$ was a 1,625-bp sequence (NCBI AC140201 pos 32,137-30,517). Both were gifts from Faith Young (University of Rochester, Rochester, New York, USA) (37).

C3d-vector for B16-melanoma cell transduction. C3d(x3) fragment was excised from the pcDNA3.1 C3d vector by BAMH1-XHO1 digest and cloned into the BAM-H1 site of the pLentilox 3.7-puro vector obtained from the Vector Core at the University of Michigan. Positive clones were confirmed by PCR and sequencing of the insert. C3d expression is driven by the CMV promotor and enhancer. Lentiviral preps were made by the Vector Core at the University of Michigan from empty vector or from C3d encoding vector. Transduced cells (controls with empty vector or C3d- expressing vector were selected by puromycin resistance, and C3d expression was confirmed by PCR of cDNA and by Western blot.

Western blot analysis. C3d protein expression by tumor cells was determined in cell lysates obtained from cells grown to approximately $1 \times 10^{6}$ cells per $\mathrm{ml}$ in $20 \mathrm{ml}$ media. Cells were lysed with RIPA Lysis Buffer supplemented with a cocktail of protease inhibitors, PMSF in DMSO and sodium orthovanadate in water (Santa Cruz Biotechnology Inc.). Protein amount in the lysates was measured by spectrophotometry using the Pierce Microplate BCA Protein Assay Kit (Pierce Biotechnology, Thermo Fisher Scientific). Cell lysates were precleared by centrifugation $(12,000 \mathrm{~g}, 15$ minutes), separated by SDS PAGE of 5-20 $\mu \mathrm{g}$ of cell lysate, under reducing conditions, on 7.5\% Tris-HCl READY GELs (Bio-Rad) followed by transfer to an Immobilon PVDF membrane (Millipore). On the blots, C3d was detected using goat anti-murine C3d antibody (R\&D systems) (1:1,000) followed by rabbit anti-goat IgG-HRP (Novus Biologicals).

Pathology and immunofluorescence. Fresh tumors were harvested in linear growth phase $\left(\sim 600 \mathrm{~mm}^{3}\right)$ embedded in optimal cutting temperature (OCT) compound (Tissue-Tek) and snap frozen. Cryo-sections (5 $\mu \mathrm{m})$ were processed, and after fixation, the slides were incubated with primary antibodies: goat anti-mouse C3d (15 $\mu \mathrm{g} / \mathrm{ml}, \mathrm{R} \& \mathrm{D}$ Systems), rat anti-mouse CD4 (GK1.5, 1:100, BD Biosciences), rat anti-mouse CD8 (53-6.7, 1:100, BD Biosciences), and anti-FoxP3 (Rabbit Polyclonal; Novus Biologicals) for 2 hours at room temperature, followed by anti-rat CF488a or anti-goat CF555 (Sigma-Aldrich) donkey secondary anti-goat IgG-AP (1:200, Southern Biotech) incubated for 1 hour at room temperature.

For unequivocal identification of transgenic C3d expression in sections, tumor cells were transfected with a C3d-HIV-ENV chimera (in-house). In tumor sections, the ENV protein was detected by immunofluorescence with human HIV Immunoglobulin (HIVIg) (NIH AIDS Research \& Reference Reagent Program Division of AIDS, NIAID, NIH — from Luiz Barbosa; diluted 1:3,000 to 1:5,000) followed by goat anti-human FITC-conjugated antibody (Southern Biotech, catalog 210-02, diluted 1:50). Sections were counterstained with a rat anti-mouse B220 antibody (RA3-6B2, BD biosciences) followed by goat anti-rat IgG $\mathrm{F}(\mathrm{ab})^{2}$ rhodamine conjugated antibody (Jackson ImmunoResearch, diluted 1:100).

No specific staining was observed in control slides stained only with the secondary antibody. Imaging was performed with a Leica DMI6000B microscope using a MicroPublisher 3.3RTV camera. For each mouse, 3 images were taken at $400 \times$ magnification, focusing on the tumor and adjacent stroma. Each section was systematically photographed in neighboring $100 \times$ fields such that $80 \%-100 \%$ of each tumor section was photographed. Total stain area/low power field, as defined by pixel area and hue, was assessed using QCapture Pro Imaging software. 
Antibodies for cell depletion and receptor/ligand blockade. T cells were depleted with anti-CD4 plus anti-CD8 $\mathrm{mAb}$ (Gk1.5 mAb [anti-CD4], $300 \mu \mathrm{g} / \mathrm{kg}$ of body weight plus 53-6.7 mAb [anti-CD8], $600 \mu \mathrm{g} / \mathrm{kg}$ of body weight; eBioscience). Antibodies were given i.p. 1 day before and every day after tumor transfer $\left(5 \times 10^{3}\right.$ cells), for the first 2 weeks, and every other day afterward until euthanasia. Mice in control groups received injections of isotype control immunoglobulin. To test whether C3d and engagement of CR2 potentiate each other in inducing tumor regression, we administered mAb anti-CR2/CR1 (mAb 7G6, eBioscience), $300 \mu \mathrm{g}, 1$ day before and every day after tumor transfer $\left(5 \times 10^{3}\right.$ cells $)$ for 2 weeks. C3d blockade was achieved with $800 \mu \mathrm{g}$ of soluble CR2-IgG1 (sCR2-IgG1) or IgG1 isotype control in PBS, administered i.v. 24 hours before inoculation of $1 \times 10^{7}$ tumor cells.

Flow cytometry and antibodies. Single cell suspensions were obtained from spleens and tumors 10 days or 18-20 days after tumor inoculation. Cells were counted and stained with allophycocyanin-conjugated (APC-conjugated) mAbs to either CD4 (GK1.5), CD8 (53-6.7), or CD19 (ID3) (BD Biosciences); phycoerythrin-conjugated (PE-conjugated) mAbs to CD21/CD35 (7G6) and to PD1 (RMPI-30) purchased from BD Biosciences; PE-conjugated mAbs to Foxp3 (FJK-16s) and FITC-conjugated Foxp3 (FJK-16s) purchased from eBioscience; and Prcp/Cy5.5-conjugated CR2/CR1 (7G6) purchased from BioLegend. Intracellular staining followed cell surface staining and was performed using eBioscience Foxp3/Transcription Factor Staining Buffer Set (catalog 00-5523-00), according to the manufacturer's instructions (Thermo Fisher Scientific, eBioscience). Intracytoplasmic cytokines were measured in T cells purified from spleens or tumors and were stained with APC-conjugated mAbs against Perforin (eBiOMAK-D), TNF $\alpha$ (MP6-XT22), and IFN $\gamma$ (XMG1.2) (eBioscience). All antibodies used in flow cytometry analysis were diluted 1:50. Four-color flow cytometric analysis of $1 \times 10^{6}$ cells was performed using a FACSCanto II (BD Biosciences).

$T$ cell isolation. Spleens were harvested from euthanized animals, and single cell suspensions were obtained by gently dissociating the splenic capsule over a $40-\mu \mathrm{m}$ filter. Red cells were depleted by incubating with ACK Lysing Buffer (Lonza), and T cells were isolated by negative selection on a $\mathrm{LS}^{+}$column, using the Pan T cell isolation kit, on a MiniMACS Separator (Miltenyi Biotec), as per manufacturer's instructions. T cell purity was assessed by flow cytometry and was always greater than $80 \%$.

Vaccination and tumor challenge. $\mathrm{C} 3 \mathrm{~d}^{+}$and $\mathrm{C} 3 \mathrm{~d}^{-}$lymphoma cells $(18-81$ pre-B cell line $(10,36)$ were thawed and grown in vitro in selection medium (RPMI 1640 with $10 \% \mathrm{FCS} ; \beta$-mercaptoethanol, $55 \mathrm{mM}$; penicillin, $100 \mathrm{U} / \mathrm{ml}$; streptomycin, $100 \mu \mathrm{g} / \mathrm{ml}$; L glutamine, 2mM; Hygromycin, $1 \mathrm{mg} / \mathrm{ml}$ ) for 6 days before use. $\mathrm{C}^{2} \mathrm{~d}^{+}$or $\mathrm{C} 3 \mathrm{~d}^{-} \mathrm{B} 16-\mathrm{F} 0$ cells were grown in RPMI1640 supplemented as detailed above with 5 $\mu \mathrm{g} / \mathrm{ml}$ of puromycin instead of hygromycin. On the day of vaccination, cells were washed and suspended in fresh medium, and viable cells were counted using Trypan Blue cell exclusion. Afterward, tumor cells were irradiated with 10 Gy (IC-320 Irradiator, BSRB, University of Michigan) and then washed twice with PBS immediately before inoculation. Vaccine inoculations were performed by i.p. injection of $5 \times 10^{6}$ lymphoma cells (twice, a week apart) into mice in the BALB/c genetic background or by a single s.c. injection of $1 \times 10^{7} \mathrm{~B} 16$ melanoma cells into C57BL/ 6 mice. Lymphoma-vaccinated mice were challenged with i.p. injection of $5 \times 10^{3}$ live tumor cells. Mice vaccinated with melanoma cells and their controls were challenged with s.c. injection of $2 \times 10^{5}$ live tumor cells 35 days after the last vaccination with $1 \times 10^{7}$ cells. Nonvaccinated melanoma mice were challenged with s.c. injection of $4 \times 10^{4}$ live tumor cells. Mice were monitored daily.

Cellular apoptosis assay. Cellular apoptosis was measured using a FAM-FLICA assay purchased from ImmunoChemistry Technologies, according to the manufacturer's instructions.

$q P C R$. RNA was obtained from Tregs isolated from recipient mice 10 days or 18-20 days following tumor transfer, with a Midi MACS T cell isolation kit (Miltenyi Biotec). Treg purity was verified by flow cytometry and found to be always greater than $90 \%$. Total RNA was prepared using PureLink RNA Mini Kit (Thermo Fisher Scientific). cDNA was produced using the VILO kit (Invitrogen, Thermo Fisher Scientific), according to the manufacturer's instructions. Real-time PCR was performed using TAQMAN primers purchased from Invitrogen. CR2-specific primers, Mm00801681_m1; CR1-specific primers; HPRT-specific primers, Mm01545399_m1; PD-1-specific primers, Mm01285676_m1; and Foxp3-specific primers, $\mathrm{Mm} 00475162$ m1. The PCR conditions were recommended by the manufacturer, $50^{\circ} \mathrm{C}, 2$ minutes, $95^{\circ} \mathrm{C}$ for 10 minutes followed by forty cycles of $95^{\circ} \mathrm{C}$ for 15 seconds and $60^{\circ} \mathrm{C}$ for 1 minute.

$T$ cell proliferation assays. T cells isolated from spleens of naive BALB/c mice were stained with Vibrant CFDA SE (Invitrogen) prior to culture. CFDA SE was reconstituted with DMSO to a final concentration of 
$5 \mathrm{mM}$. Cells were resuspended in PBS $+5 \% \mathrm{FCS}$ (Gibco) at $5 \times 10^{6} / \mathrm{ml}$ and were incubated with CFDA SE for 5 minutes at room temperature. Incubation was stopped by placing cells on ice for 5 minutes, and cells were washed twice in ice-cold 5\% FCS-RPMI and resuspended in medium with final concentration $2 \times 10^{6}$ cells $/ \mathrm{ml}$ prior to distribution into wells $\left(1 \times 10^{5}\right.$ in $100 \mu \mathrm{l} /$ well $)$ coated with $10 \mu \mathrm{g} / \mathrm{ml}$ anti-mouse CD3e (clone 145-2C11, BD Biosciences). Cells were stimulated with $1 \mu \mathrm{g} / \mathrm{ml}$ anti-mouse CD28 (clone 37.51, BD Biosciences), with $100 \mathrm{ng} / \mathrm{ml}$ recombinant human IL-2 (R\&D Systems), with or without 1:10 dilution of supernatant from $\mathrm{C} 3 \mathrm{~d}^{+}$or $\mathrm{C} 3 \mathrm{~d}^{-}$tumor cell cultures, or with or without $10 \mu \mathrm{g} / \mathrm{ml}$ anti-mouse CR1/CR2 (clone 7G6, BioLegend) $\mathrm{mAb}$ or $10 \mu \mathrm{g} / \mathrm{ml}$ isotype control, as indicated in the manuscript.

Tumor-specific killing by cytotoxic T cells. Lymphocytes from the spleens and tumors were harvested from vaccinated mice 10 days after injection of tumors, as explained above. Isolated $\mathrm{T}$ cells were cultured with tumor cells (irradiated with $10 \mathrm{~Gy}$ ) derived from the same clone that originated the tumors, in the presence of IL-2 for 6 days. Cytotoxicity was measured against C3 $\mathrm{d}^{+}$or C $3 \mathrm{~d}^{-}$targets at various effector/target ratios (E:T ratios) by a standard LDH cytotoxicity assay (Pierce, Thermo Fisher Scientific), according to the manufacturer's instructions.

Statistics. All comparisons were done with Prism-Graphpad software (v6). Comparison of survival curves was by the log rank Mantel Cox test. Averages were either compared by unpaired Student's $t$ test (2-tailed) or by nonparametric Mann Whitney $U$ test, and when appropriate, with correction for multiple comparisons by Dunn's test. We performed contingency analysis, or linear or nonlinear regression analysis, with tools available in the Prism-Graphpad software. A $P$ value less than 0.05 was considered significant.

Study approval. Animals were maintained in accordance with regulations of the University of Michigan Committee on the Use and Care of Animals under specific pathogen-free condition.

\section{Author contributions}

JLP and MC wrote the manuscript and analyzed results. MC, IS, ARL, EF, and SJB performed experiments and analyzed results. MCC discussed results, critically read the manuscript, helped with reagents, and advised on experimental protocols. TMR provided critical reagents and discussed results.

\section{Acknowledgments}

This work was supported by grants from the NIH (R21AI117561-01 and K23AI10951), the Discovery Fund of the University of Michigan Comprehensive Cancer Center, and the MTRAC KICKSTART AWARD, University of Michigan.

Address correspondence to: Marilia Cascalho, 1150 West Medical Center, SPC 5656; MSRBI A520B, Ann Arbor, Michigan 48109-5656, USA. Phone: 734.615.6817; E-mail: marilia@umich.edu.

1. Topalian SL, et al. Safety, activity, and immune correlates of anti-PD-1 antibody in cancer. N Engl J Med. 2012;366(26):2443-2454.

2. Brahmer JR, et al. Safety and activity of anti-PD-L1 antibody in patients with advanced cancer. $N$ Engl J Med. 2012;366(26):2455-2465.

3. Sharma P, Allison JP. The future of immune checkpoint therapy. Science. 2015;348(6230):56-61.

4. Carroll MC, Isenman DE. Regulation of humoral immunity by complement. Immunity. 2012;37(2):199-207.

5. Dempsey PW, Allison ME, Akkaraju S, Goodnow CC, Fearon DT. C3d of complement as a molecular adjuvant: bridging innate and acquired immunity. Science. 1996;271(5247):348-350.

6. Heesters BA, et al. Endocytosis and recycling of immune complexes by follicular dendritic cells enhances B cell antigen binding and activation. Immunity. 2013;38(6):1164-1175.

7. Balin SJ, Ross TM, Platt JL, Cascalho M. HIV genes diversify in B cells. Curr HIV Res. 2008;6(1):10-18

8. Balin SJ, Cascalho M. The rate of mutation of a single gene. Nucleic Acids Res. 2010;38(5):1575-1582.

9. Rosenberg N, Baltimore D, Scher CD. In vitro transformation of lymphoid cells by Abelson murine leukemia virus. Proc Natl Acad Sci USA. 1975;72(5):1932-1936.

10. Wabl M, Burrows PD, von Gabain A, Steinberg C. Hypermutation at the immunoglobulin heavy chain locus in a pre-B-cell line. Proc Natl Acad Sci USA. 1985;82(2):479-482.

11. Hebell T, Ahearn JM, Fearon DT. Suppression of the immune response by a soluble complement receptor of B lymphocytes. Science. 1991;254(5028):102-105.

12. Carter RH, Spycher MO, Ng YC, Hoffman R, Fearon DT. Synergistic interaction between complement receptor type 2 and membrane IgM on B lymphocytes. J Immunol. 1988;141(2):457-463.

13. Fu YX, Huang G, Wang Y, Chaplin DD. B lymphocytes induce the formation of follicular dendritic cell clusters in a lymphotoxin alpha-dependent fashion. J Exp Med. 1998;187(7):1009-1018.

14. Kemper C, Atkinson JP. T-cell regulation: with complements from innate immunity. Nat Rev Immunol. 2007;7(1):9-18.

15. Erdei A, et al. Expression and role of CR1 and CR2 on B and T lymphocytes under physiological and autoimmune conditions. 
Mol Immunol. 2009;46(14):2767-2773.

16. Molnár E, Erdei A, Prechl J. Novel roles for murine complement receptors type 1 and 2 I. Regulation of B cell survival and proliferation by CR1/2. Immunol Lett. 2008;116(2):156-162.

17. Tsoukas CD, Lambris JD. Expression of EBV/C3d receptors on T cells: biological significance. Immunol Today. 1993;14(2):56-59.

18. Kinoshita T, Takeda J, Hong K, Kozono H, Sakai H, Inoue K. Monoclonal antibodies to mouse complement receptor type 1 (CR1). Their use in a distribution study showing that mouse erythrocytes and platelets are CR1-negative. J Immunol. 1988;140(9):3066-3072.

19. Park HJ, et al. PD-1 upregulated on regulatory T cells during chronic virus infection enhances the suppression of CD8+ T cell immune response via the interaction with PD-L1 expressed on CD8+ T cells. J Immunol. 2015;194(12):5801-5811.

20. Whipple EC, et al. Low doses of antigen coupled to anti-CR2 mAbs induce rapid and enduring IgG immune responses in mice and in cynomolgus monkeys. Mol Immunol. 2007;44(4):377-388.

21. Baudino L, et al. C3 opsonization regulates endocytic handling of apoptotic cells resulting in enhanced T-cell responses to cargo-derived antigens. Proc Natl Acad Sci USA. 2014;111(4):1503-1508.

22. Surace L, et al. Complement is a central mediator of radiotherapy-induced tumor-specific immunity and clinical response. Immunity. 2015;42(4):767-777.

23. Kopf M, Abel B, Gallimore A, Carroll M, Bachmann MF. Complement component C3 promotes T-cell priming and lung migration to control acute influenza virus infection. Nat Med. 2002;8(4):373-378.

24. Kaya Z, et al. Contribution of the innate immune system to autoimmune myocarditis: a role for complement. Nat Immunol. 2001;2(8):739-745.

25. Saadi S, Wrenshall LE, Platt JL. Regional manifestations and control of the immune system. FASEB J. 2002;16(8):849-856.

26. Pio R, Corrales L, Lambris JD. The role of complement in tumor growth. Adv Exp Med Biol. 2014;772:229-262.

27. Ricklin D, Ricklin-Lichtsteiner SK, Markiewski MM, Geisbrecht BV, Lambris JD. Cutting edge: members of the Staphylococcus aureus extracellular fibrinogen-binding protein family inhibit the interaction of C3d with complement receptor 2. J Immunol. 2008;181(11):7463-7467.

28. Wang Y, et al. Autocrine Complement Inhibits IL10-Dependent T-cell-Mediated Antitumor Immunity to Promote Tumor Progression. Cancer Discov. 2016;6(9):1022-1035.

29. Rutkowski MJ, Sughrue ME, Kane AJ, Mills SA, Parsa AT. Cancer and the complement cascade. Mol Cancer Res. 2010;8(11):1453-1465.

30. Tegla CA, et al. Membrane attack by complement: the assembly and biology of terminal complement complexes. Immunol Res. 2011;51(1):45-60.

31. Corrales L, et al. Anaphylatoxin C5a creates a favorable microenvironment for lung cancer progression. J Immunol. 2012;189(9):4674-4683

32. Markiewski MM, Lambris JD. Is complement good or bad for cancer patients? A new perspective on an old dilemma. Trends Immunol. 2009;30(6):286-292.

33. Knopf PM, Rivera DS, Hai SH, McMurry J, Martin W, De Groot AS. Novel function of complement C3d as an autologous helper T-cell target. Immunol Cell Biol. 2008;86(3):221-225.

34. De Groot AS, et al. C3d adjuvant effects are mediated through the activation of C3d-specific autoreactive T cells. Immunol Cell Biol. 2015;93(2):189-197.

35. Wabl M, Burrows PD, von Gabain A, Steinberg C. Hypermutation at the immunoglobulin heavy chain locus in a pre-B-cell line Proc Natl Acad Sci USA. 1985;82(2):479-482.

36. Meyer J, Jäck HM, Ellis N, Wabl M. High rate of somatic point mutation in vitro in and near the variable-region segment of an immunoglobulin heavy chain gene. Proc Natl Acad Sci USA. 1986;83(18):6950-6953.

37. Young F, et al. Influence of immunoglobulin heavy- and light-chain expression on B-cell differentiation. Genes Dev. 1994;8(9):1043-1057. 